OPEN ACCESS

Edited by:

Zisis Kozlakidis,

International Agency For Research On

Cancer (IARC), France

Reviewed by:

Enahoro Iboi

Spelman College, United States

Venu Madhav Konala,

Ashland Bellefonte Cancer Center

$(A B C C)$, United States

*Correspondence:

Thushara Galbadage

don.galbadage@biola.edu

Specialty section:

This article was submitted to

Infectious Diseases - Surveillance,

Prevention and Treatment,

a section of the journal

Frontiers in Public Health

Received: 02 July 2020

Accepted: 12 August 2020

Published: 15 September 2020

Citation:

Jalali $A M$, Peterson $B M$ and Galbadage T (2020) Early COVID-19 Interventions Failed to Replicate 1918 St. Louis vs. Philadelphia Outcomes in the United States.

Front. Public Health 8:579559. doi: 10.3389/fpubh.2020.579559

\section{Early COVID-19 Interventions Failed to Replicate 1918 St. Louis vs. Philadelphia Outcomes in the United States}

\author{
Aliea M. Jalali ${ }^{1,2}$, Brent M. Peterson ${ }^{1}$ and Thushara Galbadage ${ }^{1 *}$ \\ ${ }^{1}$ Department of Kinesiology and Health Science, Biola University, La Mirada, CA, United States, ${ }^{2}$ College of Nursing and \\ Health Care Professions, Grand Canyon University, Phoenix, AZ, United States
}

The Coronavirus disease 2019 (COVID-19) pandemic has elicited an abrupt pause in the United States in multiple sectors of commerce and social activity. As the US faces this health crisis, the magnitude and rigor of their initial public health response was unprecedented. As a response, the entire nation shutdown at the state-level for the duration of a $\sim 1-3$ months. These public health interventions, however, were not arbitrarily decided, but rather, implemented as a result of evidence-based practices. These practices were a result of lessons learned during the 1918 influenza pandemic and the city-level non-pharmaceutical interventions (NPIs) taken across the US. During the 1918 pandemic, two model cities, St. Louis, MO, and Philadelphia, PA, carried out two different approaches to address the spreading disease, which resulted in two distinctly different outcomes. Our group has evaluated the state-level public health response adopted by states across the US, with a focus on New York, California, Florida, and Texas, and compared the effectiveness of reducing the spread of COVID-19. Our assessments show that while the states mentioned above benefited from the implementations of early preventative measures, they inadequately replicated the desired outcomes observed in St. Louis during the 1918 crisis. Our study indicates that there are other factors, including health disparities that may influence the effectiveness of public health interventions applied. Identifying more specific health determinants may help implement targeted interventions aimed at preventing the spread of COVID-19 and improving health equity.

Keywords: evidence-based practice, health disparities, coronavirus, spread, intervention, prevention, outcomes, influenza virus

\section{INTRODUCTION}

As the first wave of Coronavirus Disease 2019 (COVID-19) pandemic began to sweep through the United States (US) in March 2020, multiple public health measures were enforced across the nation in an unprecedented manner. However, by the end of June 2020, the US remained one of the largest COVID-19 epicenters, globally, with more than 2.5 million confirmed cases and the number of new daily cases reaching highs in certain states and the US (1). Now, faced with the renewed threat of experiencing prolonged second wave, many states are reintroducing partial shutdown measures, 
which are examples of non-pharmaceutical interventions (NPIs). During the first wave of this pandemic, the US strictly implemented multiple NPIs to help mitigate the spread of the disease and reduce the number of COVID-19-related deaths. Herein we discuss the successes and failures of the implemented evidence-based public health practices amid a nationwide public health crisis that abruptly brought the nation and its economy to a screeching halt.

As of February 2020, while China, Italy, and Spain experienced the turmoil of being the epicenters for the COVID-19 pandemic, the US had only about 50 confirmed cases, and the national populace was nearly unaffected. No one could have anticipated how life was about to change in the ensuing months. In March 2020, different states started to sound the alarms and place their respective constituencies under states of emergency (2-4). After that, increasingly rigorous preventative measures that affected the function and dynamics of societal interaction were implemented. These interventions, aimed at facilitating social distancing and preventing the spread of COVID-19, can be categorized into four broad measures $(5,6)$. These are (1) screening and testing, (2) prevention of mass gatherings, (3) stay at home orders, and (4) the use of face masks. In the US, 44 states of the 50 states implemented statewide stay at home orders at the early stages of the COVID-19 pandemic, paralleling other measures listed above (Figure 1, Supplemental Table 1). The mean duration of stay at home orders for all US states was 49.5 days ( $\mathrm{SD} \pm 16.5$ ) (median 50 days, range 25-81 days).

While seemingly sudden and societally intrusive, historical precedent and evidence-based practices have guided these measures. For example, a century ago, the world experienced a devastating toll on lives caused by the 1918 influenza pandemic. In response to this pandemic, health officials implemented a broad range of NPIs according to the then available understanding of disease transmission (8-10). Furthermore, studies comparing public health measures implemented by several cities across the United States and other nations such as England further illustrated how these measures helped reduce the spread of the 1918 influenza pandemic and decrease mortality rates $(11-14)$.

Studies on the 1918 influenza pandemic have focused on contrasting NPIs implemented by two US cities, St. Louis, MO, and Philadelphia, PA. St. Louis imposed strict preventative interventions early on, while Philadelphia minimally applied restrictions at a much later date. Accordingly, St. Louis had a milder outbreak, whereas Philadelphia experienced significantly higher mortality rates (14). These outcomes observed in the 1918 influenza pandemic helped guide the widely-adopted rigorous public health measures against COVID19. Hatchett et al. (14) also identified four critical factors that helped determine the success of the control of the pandemic dissemination. These factors were (1) implementation of early and rapid interventions, (2) duration of the responses, (3) multiple concurrent interventions, and (4) the intensity of the interventions implemented.

Other studies supported these conclusions while emphasizing the effectiveness of early interventions, but also noted that stringent preventative measures could leave many more susceptible individuals once these NPIs are relaxed $(12,15)$. During the 1918 pandemic, most of the US cities maintained preventative measures for about 2-8 weeks (14). However, cities that relaxed NPIs earlier experienced increased case numbers resulting in second wave resurgences. An inverse relationship between the intensity of the first and second waves of the pandemic was also observed. These observations were partly due to the smaller proportion of susceptible populations present in cities after a strong first wave of the disease $(12,14)$.

Here we compare and contrast public health interventions implemented in the US during the first wave of the COVID19 pandemic, focusing on four states: New York, Florida, Texas, and California. These states included most of the populous US counties and were affected sharply by the early stages of the COVID-19 pandemic. In addition, we studied the case rates of COVID-19 before, during, and after these measures were implemented, and then compared it to the outcomes of St. Louis, and Philadelphia, during the 1918 influenza pandemic (Figure 2). While variation in the timing and the intensity of the public health measures applied was observed, all four states implemented very similar interventions. Our comparisons show that the early evidence-based interventions implemented by the US were not adequately able to replicate the desired outcomes of St. Louis vs. Philadelphia and curtail the COVID-19 pandemic.

\section{PUBLIC HEALTH RESPONSE TO COVID-19}

As mentioned earlier, responses to earlier pandemics in the US included school closures, restaurant restrictions, emergency declarations, gathering restrictions, stay at home orders, and non-essential business closures (16). The COVID-19related responses have been mainly relegated to state-level decision making and based on necessity and intensity within each state. To characterize the state-level COVID-19 interventions, we compared and contrasted the broad measured implemented by the states of California, Florida, New York, and Texas.

\section{Screening and Testing}

Targeted screening for COVID-19 began in California and New York with Los Angeles (LAX), San Francisco (SFO), and New York (JFK) airports for travelers coming from Wuhan, China, starting on January 17th (17). The first reported case in the US occurred on January 26th in California. New York, Florida, and Texas all had initial cases within the 1st week of March (Figure 1C). Early in the pandemic, testing was limited, and priority was given to high-risk individuals, including symptomatic patients, healthcare workers, first responders, essential workers, and individuals in contact with other highrisk individuals. As more tests were readily available, fewer restrictions were placed on who was able to get tested [Florida Department of (18-21)]. In addition to walk-up and drivethrough sites, mobile testing sites were also deployed in Florida and New York to increase the number of tests administered $(22,23)$. Each state also implemented contact tracing to identify potentially exposed individuals (24). 


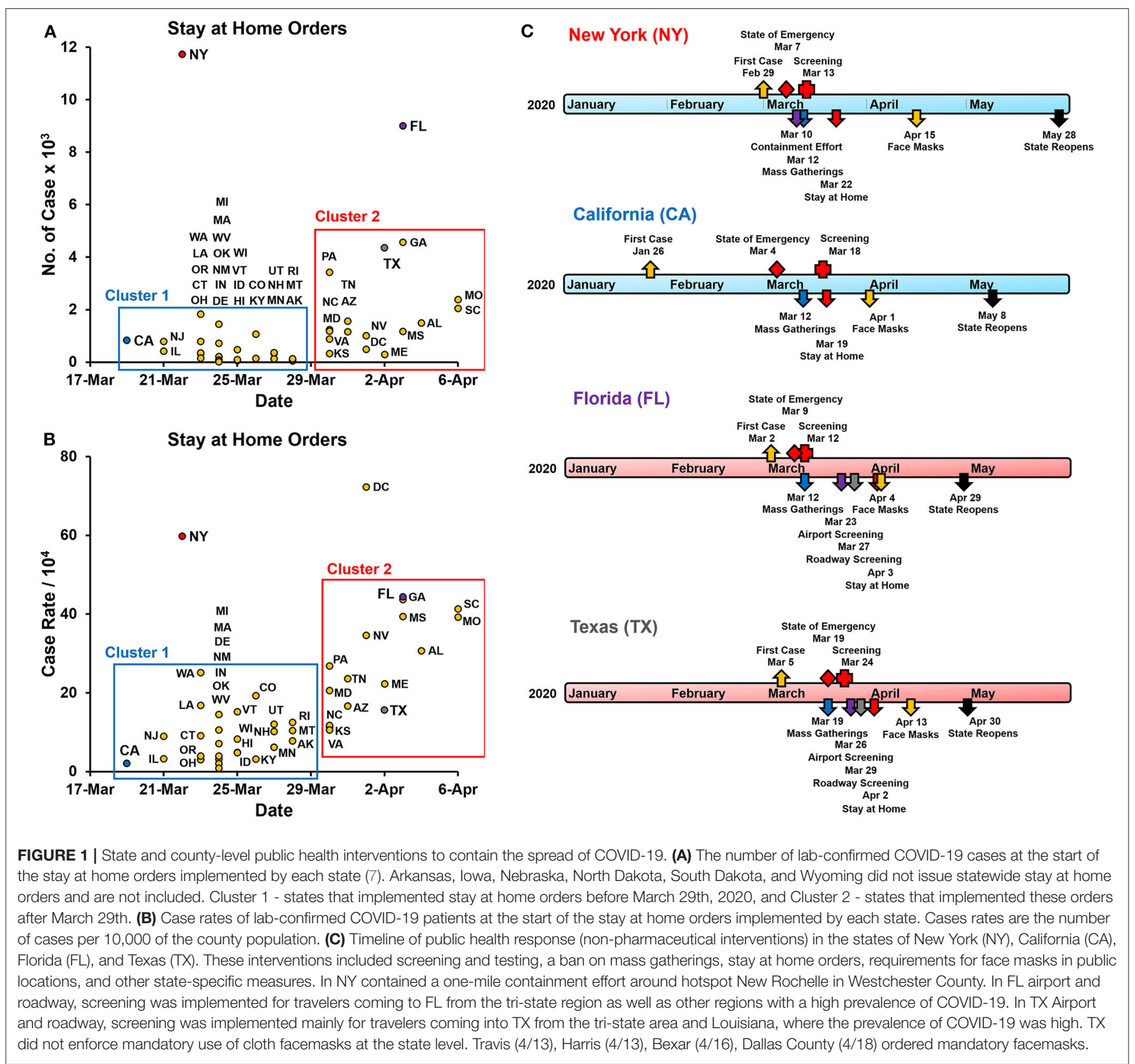

\section{Mass Gatherings}

The next primary public health intervention implemented across all four states was the cancellation of mass gatherings of 250 individuals, followed by 50 individuals per location (Supplemental Tables 2-5). These orders followed shortly after initial cases were identified in each state. Events that brought in large amounts of attendance, such as concerts, sporting events, and festivals were canceled first. Next, the states incrementally decreased the number of people allowed to gather in one location until, eventually, the state recommended that people should only interact with those who were within the same household.

\section{Stay at Home Orders}

One of the most rigorous measures utilized during COVID19 was the stay at home orders. California was under stay at home order for 50 days (March 19th to May 7th) (25). The stay at home order in California was implemented more rigorously at the county level because the state-level order acted more as a recommendation (Supplemental Table 3). The NY "State on PAUSE" plan stay at home order was enforced for 68 days (March 22nd to May 28th) before the state started its Phase one reopening plan (26-28). Florida state stay at home order was in effect for 27 days (April 3rd to April 29th) (29). Texas implemented a stay at 


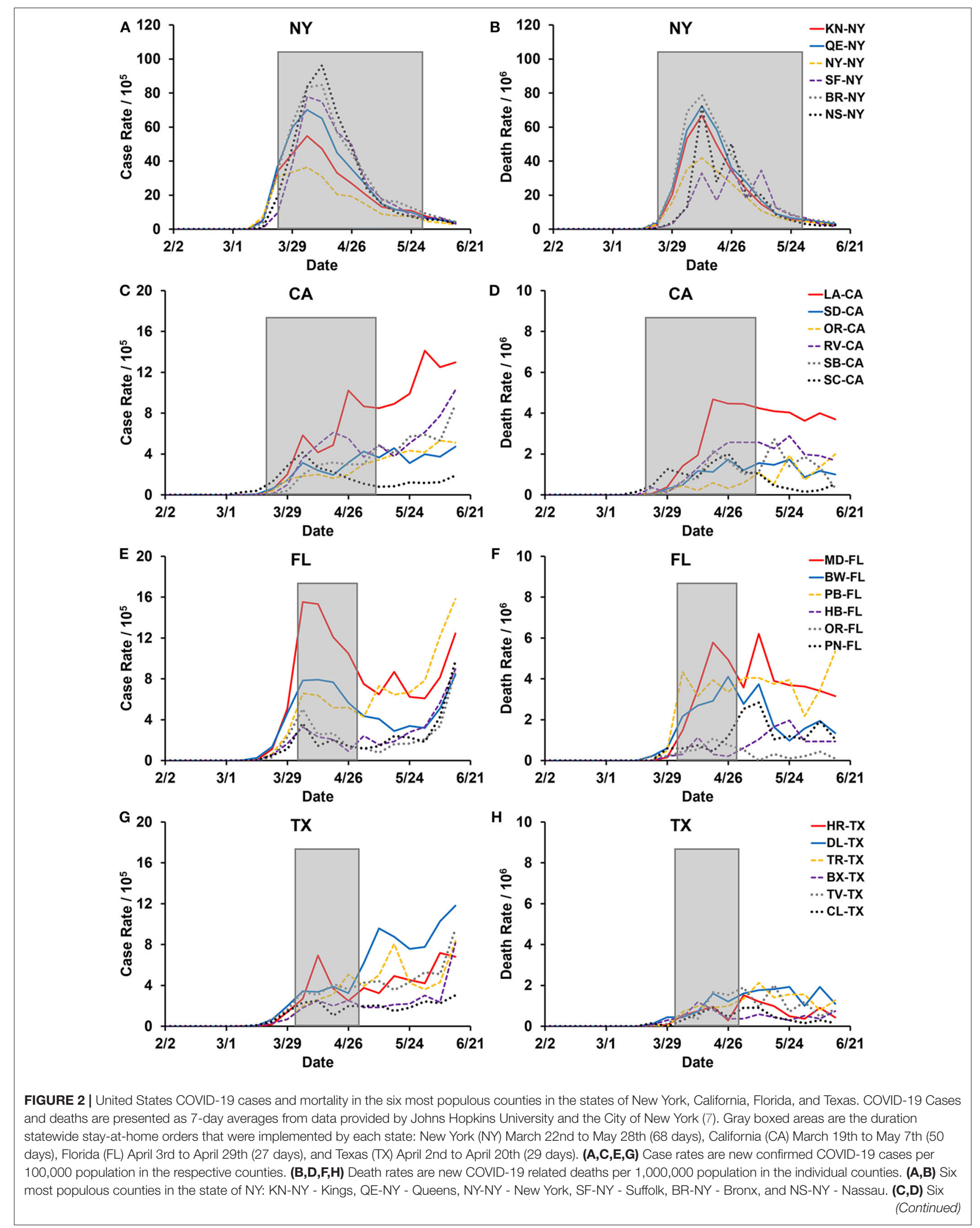


FIGURE 2 | most populous counties in the state of CA: LA-CA - Los Angeles, SD-CA - San Diego, OR-CA - Orange, RV-CA - Riverside, SB-CA - San Bernardino, and SC-CA - Santa Clara. (E,F) Six most populous counties in the state of FL: MD-FL - Miami-Dade, BW-FL - Broward, PB-FL - Palm Beach, HB-FL - Hillsborough, OR-FL - Orange, and PN-FL - Pinellas. (G,H) Six most populous counties in the state of TX: HR-TX - Harris, DL-TX - Dallas, TR-TX - Tarrant, BX-TX - Bexar, TV-TX Travis, and CL-TX - Collin.

home order for 29 days before relaxing these measures statewide (April 2nd to April 30th) (30).

Many US states enacted stay at home orders very early on in the COVID-19 transmission. States with early COVID19 cases placed these measures before April 29th (cluster 1) and did so with a statewide case count of fewer than 2,000 cases, while states that put stay at home orders after April 29th did so before reaching 5,000 cases (cluster 2) (Figure 1A, Supplemental Table 1). When adjusted to the county population, these measures were implemented with case rates of below 50 cases per 10,000 (Figure 1B). The only exception was New York, which implemented these measures after 11,700 cases were confirmed (Figure 1A).

\section{Cloth Face Masks}

On April 3rd, the Centers for Disease Control and Prevention (CDC) released its recommendation for all individuals to use cloth face masks when in public (31). The goal of this recommendation was to reduce the viral transmission from asymptomatic carriers that may unknowingly spread to disease to susceptible individuals $(5,32)$. While the extent to which the effectiveness of this measure is debatable, it helps bring more awareness to the public and help curtail the person-toperson transmission of the virus (33). California was the first to implement this statewide on April 1st, which was 2 days before the CDC's recommendation (Figure 1C). New York also implemented this measure as a state-level order, but it happened 2 weeks after the CDC's recommendation. Florida and Texas only recommended face coverings at the state-level but was mandated in most counties (Supplemental Tables 4, 5).

\section{DIFFERENCES IN STATEWIDE RESPONSES TO COVID-19}

The public health interventions implemented across the four states, New York, California, Florida, and Texas, were very similar. Any differences stem from the relative time of implementation and the intensity of measures taken. Unfortunately, New York was one of the first states severely affected by COVID-19 and was likely too late to implement these preventative measures (Figures 1A,B, 2B). The initial wave of COVID-19 in New York, therefore, resembled that of Philadelphia during the 1918 pandemic. California, on the other hand, initiated precautionary measures early and seemed to follow the outcomes of St. Louis, at least in the initial stages (Figures 2C,D). Regulations in both of these states were more stringent, and often had consequences such as fines and jail time tied to not adhering to them.

In Texas and Florida, the implementation of specific public health interventions was less rigorous as compared to California and New York. In Texas, for example, the regulations were not implemented as quickly or as firmly at the state-level. Some public health interventions, such as the ban on gathering, stay at home orders, and wearing cloth face masks, may have been perceived as violations of individual liberties and disrupting businesses. In many ways, the small-government philosophy of these states left essential decisions and actions to be made at the county-level. Around the time many states went into shut down mode, spring break activities remained open in Florida. The decision to not shut down before spring break was made in support of the state's economy. It was only after large tourist attractions, including Universal Studios and Disney World, decided to close were more rigorous measures put in place in Florida.

\section{THE SPREAD OF COVID-19 ACROSS STATES AND COUNTIES}

During the 1st months of COVID-19, the disease spread rapidly across the United States. In New York, the number of positive cases grew exponentially over the 1st month of the pandemic, especially in the New York City area and surrounding boroughs. However, unlike other states, the number of daily cases in New York has decreased consistently since the end of April. In California, Florida, and Texas, the number of daily cases has continued to increase over time at a slower rate compared to New York. To better understand the dynamics of COVID-19 spread in each of these states, we reviewed the number of cases and deaths in the six most populous counties in each of these states (Figure 2).

In New York, the most populous counties all experienced a similar first wave of COVID-19, with a peak of about 100 cases per 10,000 people in early April (Figure 2A). Most counties in the state of California continued to have a relatively slow, but steady rise in the number of cases, making it difficult to distinguish between a first and a second wave (Figure 2C). We observed a similar pattern in the counties in Florida and Texas, except Miami-Dade County in Florida, which showed a peak case rate of about 15 cases per 10,000 people in early April (Figures 2C,E,G). Among these states, it is clear that New York experienced a robust first wave and a negligible second wave of the COVID-19 pandemic. While California, Florida, and Texas were spared from a significant first wave with cases rate peaking at $<20$ cases per 10,000 , they are now facing a much higher risk for a prolonged second wave of the disease.

\section{US COVID-19 INTERVENTIONS FAILED TO REPLICATE 1918 PANDEMIC OUTCOMES}

In the COVID-19 pandemic, the goal of effective public health preventative measures implemented was to mitigate and contain the spread of the disease. In the US, for the most part, public 
health interventions followed the principles of effective NPIs. They were implemented early on in the pandemic, using multiple preventative measures, with high intensity and for average durations longer than 45 days (Figure 1, Supplement Table 1). The exception to this was New York, which delayed the initiation of these measures (Figures 1A,B). This caused New York to experience a peak first wave, with hospitals reaching their capacity and a peak number of deaths occurring during midApril (Figure 1B). However, New York enforced its preventative measures for close to 3 months, which in turn helped them bring their daily case rates to $<5$ cases per 10,000 by the end of June.

In contrast to New York, most other states followed the evidence-based recommendations, as stated above (Figure 1). This helped states "flatten the curve" to various degrees and control the initial spread of COVID-19 within their states. However, these public health interventions seemed to have also prolonged the transmission potential of the COVID-19 as states, including California, Florida, and Texas were experiencing new daily highs in confirmed cases by the end of June 2020 (1). While the general expectation was that US states would follow the outcome of St. Louis during the 1918 pandemic, they have fallen short of replicating this desired outcome. On the contrary, by the end of June 2020, many such states were reimplementing statewide partial shutdown measures to prevent a potential second wave of COVID-19.

\section{DISCUSSION}

While the United States failed to prevent the early spread of COVID-19 effectively, some countries had better success containing the Coronavirus with their public health interventions. In Iceland, for example, when cases were identified, public health officials implemented the following strategies: quarantine requirements for international travelers, rigorous tracing of infection, ban on gatherings larger than 20 persons, school closures with limited openings of elementary and preschools, defining areas of higher risk, and regular communication with the general public (34). New Zealand, another island nation with great success, was more rigorous in the process by modifying and intensifying pre-existing plans for the management of influenza pandemics from previous outbreaks (35). These methods included the declaration of a national emergency, a nationwide lockdown, closure of nonessential work locations, banning social gatherings, extreme restrictions on travel, and closure of all schools. Furthermore, as part of this intensified strategy, border security was also tightly regulated. However, there are distinct differences between Iceland, New Zealand, and the United States. Iceland and New Zealand are small island nations with much smaller populations, making it much easier to implement rigorous preventative measures, including better travel restrictions and contact tracing. They were also able to coordinate their public health response more consistently nationwide, unlike the US, which enforced COVID-19 interventions mainly at the state level.

Several factors can help explain why the US was unable to effectively replicate the outcomes of St. Louis vs. Philadelphia during the 1918 flu pandemic. These include (1) the level of adherence to these implemented preventative measures and social behaviors, (2) disparities in social determinants of health, and (3) extensive global and domestic travel with little restrictions. Regardless of the public health intervention intensity, they can be ineffective if people do not consistently adhere to them. Besides, numerous risk factors have been identified for COVID-19 and its clinical outcomes. These include advanced age, sex, immune-compromised status, and comorbidities, including chronic respiratory diseases, diabetes, and hypertension (36-38). American Indians, African Americans, and Hispanic individuals have been reported to be four to five times more likely to be hospitalized for COVID-19 when compared to non-Hispanic whites (39). Disparities in social determinants of health, such as access to healthcare, uninsured population, employment, poverty, education, and population density, can also contribute to the differences observed in COVID-19 transmission. Potential clusters of these risk factors and health determinates present in different geographic regions can lead to the disproportionate spread of the Coronavirus. In conclusion, it is crucial to consider factors such as adherence to preventative measures, and health disparities, in evaluating the effectiveness of COVID-19 interventions implemented. These factors likely caused the US early COVID-19 public health measures to be less effective in containing the Coronavirus pandemic and is an important further direction of research.

\section{DATA AVAILABILITY STATEMENT}

All datasets generated for this study are included in the article/Supplementary Material.

\section{AUTHOR CONTRIBUTIONS}

$\mathrm{AJ}$ analyzed the US public health response and helped with the figure preparation, writing, and editing of the manuscript. BP aided in intervention comparative analysis and helped with the writing and editing of the manuscript. TG aided in disease spread, comparative analysis, helped with the figure preparation, writing, and editing of the manuscript. All authors contributed to the article and approved the submitted version.

\section{ACKNOWLEDGMENTS}

We thank Drs. Richard S. Gunasekera, Genti Buzi, and Biola research students JongWon See, Alexis M. Gulsvig, and Sumaia G. Khoury for their discussions and data analysis on this research topic. We also thank Dr. Jeffrey S. Wang, Infectious Disease Specialist at Kaiser Permanente, Anaheim, California, for his clinical insights.

\section{SUPPLEMENTARY MATERIAL}

The Supplementary Material for this article can be found online at: https://www.frontiersin.org/articles/10.3389/fpubh. 2020.579559/full\#supplementary-material 


\section{REFERENCES}

1. CDC. Coronavirus Disease 2019 (COVID-19) Cases in the U.S. Centers for Disease Control and Prevention. (2020) Available online at: https://www. cdc.gov/coronavirus/2019-ncov/cases-updates/cases-in-us.html (accessed August 10, 2020).

2. Hogan GL. Governor Larry Hogan Declares State of Emergency, Expands Statewide Response to Novel Coronavirus. Office of Governor. (2020). Available online at: https:/governor.maryland.gov/2020/03/05/governorlarry-hogan-declares-state-of-emergency-expands-statewide-response-tonovel-coronavirus/ (accessed August 10, 2020).

3. Inslee GJ. Inslee Issues COVID-19 Emergency Proclamation. Office of Governor. (2020). Available online at: https://www.governor.wa.gov/newsmedia/inslee-issues-covid-19-emergency-proclamation (accessed August 10, 2020).

4. Newsom GG. Governor Newsom Declares State of Emergency to Help State Prepare for Broader Spread of COVID-19. Office of Governor. (2020). Available online at: https://www.gov.ca.gov/2020/03/04/governor-newsomdeclares-state-of-emergency-to-help-state-prepare-for-broader-spread-ofcovid-19/ (accessed August 10, 2020).

5. Galbadage T, Peterson BM, Gunasekera RS. Does COVID-19 spread through droplets alone? Front Public Health. (2020) 8:163. doi: 10.3389/fpubh. 2020.00163

6. Wilder-Smith A, Freedman DO. Isolation, quarantine, social distancing and community containment: pivotal role for old-style public health measures in the novel coronavirus (2019-nCoV) outbreak. J Travel Med. (2020) 27:taaa020. doi: $10.1093 / \mathrm{jtm} / \mathrm{taaa} 020$

7. Dong E, Du H, Gardner L. An interactive web-based dashboard to track COVID-19 in real time. Lancet Infect Dis. (2020) 20:533-4. doi: 10.1016/s1473-3099(20)30120-1

8. Mills CE, Robins JM, Lipsitch M. Transmissibility of 1918 pandemic influenza. Nature. (2004) 432:904-6. doi: 10.1038/nature03063

9. Ferguson NM, Cummings DA, Cauchemez S, Fraser C, Riley S, Meeyai A, et al. Strategies for containing an emerging influenza pandemic in Southeast Asia. Nature. (2005) 437:209-14. doi: 10.1038/nature04017

10. Markel H, Stern AM, Navarro JA, Michalsen JR, Monto AS, DiGiovanni C. Nonpharmaceutical influenza mitigation strategies, US communities, 1918-1920 pandemic. Emerg Infect Dis. (2006) 12:1961-4. doi: 10.3201/eid1212.060506

11. Ferguson NM, Cummings DA, Fraser C, Cajka JC, Cooley PC, Burke DS. Strategies for mitigating an influenza pandemic. Nature. (2006) 442:448-52. doi: $10.1038 /$ nature 04795

12. Bootsma MC, Ferguson NM. The effect of public health measures on the 1918 influenza pandemic in U.S. cities. Proc Natl Acad Sci USA. (2007) 104:7588-93. doi: 10.1073/pnas.0611071104

13. Handel A, Longini IM Jr, Antia R. What is the best control strategy for multiple infectious disease outbreaks? Proc Biol Sci. (2007) 274:833-7. doi: $10.1098 / \mathrm{rspb} .2006 .0015$

14. Hatchett RJ, Mecher CE, Lipsitch M. Public health interventions and epidemic intensity during the 1918 influenza pandemic. Proc Natl Acad Sci USA. (2007) 104:7582-7. doi: 10.1073/pnas.06109 41104

15. Kalnins I. The Spanish influenza of 1918 in St. Louis, Missouri. Pub Health Nurs. (2006) 23:479-83. doi: 10.1111/j.1525-1446.2006.00586.x

16. Gupta S, Nguyen TD, Rojas FL, Raman S, Lee B, Bento A, et al. Tracking Public and Private Responses to the COVID-19 Epidemic: Evidence from State and Local Government Actions. National Bureau of Economic Research. (2020).

17. CDC. Public Health Screening to Begin at 3U.S. Airports for 2019 Novel Coronavirus ("2019-nCoV”). Centers for Disease Control and Prevention. (2020). Available online at: https://www.cdc.gov/media/ releases/2020/p0117-coronavirus-screening.html (accessed August 10, 2020)

18. Florida Department of Health. Clinical Screening Tool for Identifying Persons Under Investigation. (2020). Available online at: https://floridahealthcovid19. gov/health-care-providers/ (accessed August 10, 2020).
19. State of California. Testing and Treatment. (2020). Available online at: https://covid19.ca.gov/testing-and-treatment/ (accessed August 10, 2020).

20. State of New York. COVID-19 Testing. (2020). Available online at: https://coronavirus.health.ny.gov/covid-19-testing (accessed August 10, 2020).

21. Texas Department of State Health Services. COVID-19 Testing Information. (2020). Available online at: https://www.dshs.state.tx.us/coronavirus/testing. aspx (accessed August 10, 2020).

22. City of New York. NYC COVID-19 Citywide Information Portal. (2020). Available online at: https://www1.nyc.gov/site/ coronavirus/get-tested/covid-19-testing.page (accessed August 10, 2020).

23. Florida Division of Emergency Management. Florida COVID-19 Mobile Testing Lab. (2020). Available online at: https://flcovidtest-floridadisaster.hub. arcgis.com/ (accessed August 10, 2020).

24. CDC. Coronavirus Disease 2019 (COVID-19) COVIDTracer 1.0. Centers for Disease Control and Prevention. (2020). Available online at: https://www. cdc.gov/coronavirus/2019-ncov/php/contact-tracing/COVIDTracer.html (accessed August 10, 2020).

25. State of California. Stay Home QઐA. (2020). Available online at: https:// covid19.ca.gov/stay-home-except-for-essential-needs/ (accessed August 10, 2020).

26. Cuomo GAM. No. 202.31: Continuing Temporary Suspension and Modification of Laws Relating to the Disaster Emergency. (2020). Available online at: https://www.governor.ny.gov/news/no-20231-continuingtemporary-suspension-and-modification-laws-relating-disaster-emergency (accessed August 10, 2020).

27. State of New York. New York State on PAUSE. (2020). Available online at: https://coronavirus.health.ny.gov/new-york-state-pause (accessed August 10, 2020).

28. State of New York. Reopening New York. (2020). Available online at: https:// forward.ny.gov/ (accessed August 10, 2020).

29. State of Florida. Executive Order Number 20-91 (Essential Services and Activities During COVID-19 Emergency). (2020). Available online at: https:// www.flgov.com/wp-content/uploads/orders/2020/EO 20-91-compressed.pdf (accessed August 10, 2020).

30. Abbott GG. Executive Order GA14 (Relating to Statewide Continuity of Essential Services Aizd Activities During the COVID19 Disaster). (2020). Available online at: https://lrl.texas.gov/ scanned/govdocs/Greg\%20Abbott/2020/GA-14.pdf (accessed August 10, 2020).

31. CDC. Considerations for Wearing Cloth Face Coverings. Centers for Disease Control and Prevention. (2020). Available online at: https://www.cdc.gov/ coronavirus/2019-ncov/prevent-getting-sick/cloth-face-cover-guidance. html (accessed August 10, 2020).

32. Esposito S, Principi N, Leung CC, Migliori GB. Universal use of face masks for success against COVID-19: evidence and implications for prevention policies. Eur Respir J. (2020) 55:2001260. doi: 10.1183/13993003. 01260-2020

33. Eikenberry SE, Mancuso M, Iboi E, Phan T, Eikenberry K, Kuang Y, et al. To mask or not to mask: modeling the potential for face mask use by the general public to curtail the COVID-19 pandemic. Infect Dis Model. (2020) 5:293-308. doi: 10.1016/j.idm.2020.04.001

34. Iceland Directorate of Health. Iceland's Response: Government objectives and actions. (2020). Available online at: https:// www.covid.is/sub-categories/icelands-response (accessed August 10, 2020).

35. Baker MG, Kvalsvig A, Verrall AJ. New Zealand's COVID-19 elimination strategy. Med J Aust. (2020). doi: 10.5694/mja2.50735. [Epub ahead of print].

36. Galbadage T, Peterson BM, Awada J, Buck AS, Ramirez DA, Wilson J, et al. Systematic review and meta-analysis of sex-specific COVID19 clinical outcomes. Front Med. (2020) 7:348. doi: 10.3389/fmed.2020. 00348

37. Li LQ, Huang T, Wang YQ, Wang ZP, Liang Y, Huang TB, et al. COVID-19 patients' clinical characteristics, discharge rate, and fatality 
rate of meta-analysis. J Med Virol. (2020) 92:577-83. doi: 10.1002/jmv. 25757

38. Richardson S, Hirsch JS, Narasimhan M, Crawford JM, McGinn T, Davidson KW, et al. Presenting characteristics, comorbidities, and outcomes among 5700 patients hospitalized with COVID-19 in the New York city area. JAMA. (2020) 323:2052-9. doi: 10.1001/jama. 2020.6775

39. CDC. COVID-19 in Racial and Ethnic Minority Groups. (2020). Centers for Disease Control and Prevention. Available online at: https://www.cdc.gov/ coronavirus/2019-ncov/need-extra-precautions/racial-ethnic-minorities. html (accessed August 10, 2020).
Conflict of Interest: The authors declare that the research was conducted in the absence of any commercial or financial relationships that could be construed as a potential conflict of interest.

Copyright (c) 2020 Jalali, Peterson and Galbadage. This is an open-access article distributed under the terms of the Creative Commons Attribution License (CC BY). The use, distribution or reproduction in other forums is permitted, provided the original author(s) and the copyright owner(s) are credited and that the original publication in this journal is cited, in accordance with accepted academic practice. No use, distribution or reproduction is permitted which does not comply with these terms. 